\title{
Can you Park your Scooter There? Why Scooter Riders Mispark and What to do about it
}

\author{
Anne Brown ${ }^{1}$ (D), Nicholas J. Klein ${ }^{2}$ (D), Calvin Thigpen ${ }^{3}$ (D) \\ ${ }^{1}$ School of Planning, Public Policy, and Management, University of Oregon, ${ }^{2}$ Department of City and Regional Planning, Cornell University, ${ }^{3}$ Lime \\ Keywords: parking, micromobility, e-scooter, pedestrian, access, perceptions \\ https://doi.org/10.32866/001c.19537
}

Findings

Policymakers, the media, and the public often view e-scooters as sidewalk clutter.

While research suggests that concerns about misparked scooters are overblown, understanding why travelers mispark could inform interventions to increase parking compliance. We surveyed 391 international scooter users and find that few (9\%) reported ever misparking, while another 19 percent were unsure. Our findings suggest that riders are largely unfamiliar with local parking regulations; instead, they define parking correctness based on an intuitive concern over impeding access of other travelers. According to respondents, in-app reminders, additional infrastructure, signage, and fines would be the most effective interventions to improve parking compliance.

\section{Questions}

Introduced in 2017, dockless e-scooters ("scooters") now operate on the streets and sidewalks in hundreds of cities worldwide. Along with safety, scooter parking is a continual source of consternation in cities, with complaints about scooter "clutter" regularly reported in popular media (Gössling 2020), commonly cited in public complaints (e.g., Portland Bureau of Transportation 2018) and, in some cases, motivating the suspension of scooter pilot programs altogether (e.g., Livingston 2020). Despite the outcry over misparked scooters, researchers repeatedly find low rates of improper scooter parking. Research conducted in seven cities across the United States found that between 1.7 and 8 percent of scooters block pedestrian or ADA access (Brown et al. 2020; Fang et al. 2018; James et al. 2019; Portland Bureau of Transportation 2018). Though perceptions of and concerns around scooter misparking appear over-blown relative to observed rates of misparking, riders can still improve their parking behavior. To this end, we administered a survey to Lime scooter users in five international cities to understand:

1. Why do people mispark scooters?

2. What do people think we can do to incentivize proper scooter parking behaviors?

\section{Methods}

We administered an online survey in December 2020 to Lime users in five cities: Auckland, New Zealand; Cologne, Germany; Milton Keynes, England; Nashville, U.S.; and Rome, Italy. We administered the survey in English, German, and Italian to users who had used a scooter in the previous six months. Four hundred and thirty-one respondents started the survey, 358 
completed it ( $1 \%$ of riders invited to participate via email responded). For this analysis, we restrict our sample to the 391 respondents who completed at least 25 percent of the survey (Auckland $n=46$; Cologne $n=80$; Milton Keynes $n$ $=167$; Nashville $\mathrm{n}=20$; and Rome $\mathrm{n}=78$ ) (Data and code repository: Klein, Thigpen, and Brown 2021).

We surveyed respondents about:

- their knowledge of scooter parking regulations in their city;

- whether, why, and how often they have parked a scooter improperly;

- what interventions they think would most effectively encourage proper parking behaviors.

Consistent with reported scooter user demographics (Portland Bureau of Transportation 2018), survey respondents were disproportionately young and male. Most (73\%) were employed full-time, and seven percent were students. Thirty-five percent of respondents had taken ten or more total scooter trips ever. In addition, 55 percent used scooters less than once per week before the COVID-19 pandemic, and 35 percent were new users since the pandemic. The majority had access to at least one car (80\%) and bicycle (67\%).

\section{Findings}

\section{Why do people mispark scooters?}

Most survey respondents (73\%) reported that they have never parked a scooter improperly, 19 percent were unsure, and just nine percent said they had ever parked a scooter improperly. Of those who said they always parked properly, the majority (61\%) said the most important reason was that "I care about how my parking might affect other travelers," followed by insufficient parking and no parking close to their destination (14\%), and knowing the parking rules $(7 \%)$.

Among those who had misparked, the most important reasons were related to understanding the rules: "not know[ing] what the rules about scooter parking are" (35\%) and "the rules about scooter parking were unclear" (33\%). A smaller number of respondents cited insufficient space (13\%), doing what everyone else was doing (8.7\%), and being in a hurry (6.5\%).

We also tested respondents' knowledge of parking regulations by showing respondents eight images of scooters parked in different positions and asking whether these scooters were parked properly. Table 1 and Figure 1 summarize the "quiz" results, with the correct answer identified in bold for each city. 
Table 1. Scooter riders' assessments of parking compliance for eight scenarios.

\begin{tabular}{|c|c|c|c|c|c|c|c|}
\hline & $\begin{array}{l}\text { Overall, } \\
\mathrm{N}=391\end{array}$ & $\begin{array}{l}\text { Auckland, } \\
\mathrm{N}=46\end{array}$ & $\begin{array}{l}\text { Cologne, } \\
N=80\end{array}$ & $\begin{array}{l}\text { Milton Keynes, } \\
\qquad N=167\end{array}$ & $\begin{array}{l}\text { Nashville, } \\
\mathrm{N}=20\end{array}$ & $\begin{array}{l}\text { Rome, } \\
N=78\end{array}$ & Correct \\
\hline Tipped Over & & & & & & & $78 \%$ \\
\hline Parked improperly & 384 (98\%) & 44 (98\%) & $80(100 \%)$ & 163 (98\%) & 20 (100\%) & 77 (99\%) & \\
\hline Parked properly & $6(1.5 \%)$ & $1(2.2 \%)$ & $0(0 \%)$ & $4(2.4 \%)$ & $0(0 \%)$ & $1(1.3 \%)$ & \\
\hline Curb Cut & & & & & & & $96 \%$ \\
\hline Parked improperly & $376(96 \%)$ & $46(100 \%)$ & 75 (94\%) & $159(95 \%)$ & 20 (100\%) & 76 (99\%) & \\
\hline Middle of Sidewalk & & & & & & & $92 \%$ \\
\hline Parked improperly & $360(92 \%)$ & $41(89 \%)$ & 78 (98\%) & 152 (92\%) & $16(80 \%)$ & 73 (94\%) & \\
\hline Parked properly & $30(7.7 \%)$ & $5(11 \%)$ & $2(2.5 \%)$ & $14(8.4 \%)$ & $4(20 \%)$ & $5(6.4 \%)$ & \\
\hline Blocking Door & & & & & & & $90 \%$ \\
\hline Parked improperly & 353 (90\%) & 41 (89\%) & 75 (94\%) & $150(90 \%)$ & $16(80 \%)$ & 71 (91\%) & \\
\hline Parked properly & 38 (9.7\%) & $5(11 \%)$ & $5(6.2 \%)$ & $17(10 \%)$ & $4(20 \%)$ & $7(9.0 \%)$ & \\
\hline Street Furniture / Curb Zone & & & & & & & $47 \%$ \\
\hline Parked properly & 222 (57\%) & $26(57 \%)$ & $48(60 \%)$ & $84(50 \%)$ & $13(65 \%)$ & $51(65 \%)$ & \\
\hline Against Wall & & & & & & & $62 \%$ \\
\hline Parked improperly & $150(38 \%)$ & 15 (33\%) & 31 (39\%) & $46(28 \%)$ & $9(45 \%)$ & 49 (63\%) & \\
\hline Parked properly & $240(62 \%)$ & $31(67 \%)$ & 49 (61\%) & $120(72 \%)$ & $11(55 \%)$ & $29(37 \%)$ & \\
\hline Empty Plaza & & & & & & & $58 \%$ \\
\hline Parked improperly & 145 (37\%) & $13(28 \%)$ & 32 (40\%) & 78 (47\%) & $4(20 \%)$ & $18(23 \%)$ & \\
\hline Parked properly & 246 (63\%) & $33(72 \%)$ & $48(60 \%)$ & 89 (53\%) & 16 (80\%) & 60 (77\%) & \\
\hline Bike Rack & & & & & & & $58 \%$ \\
\hline Parked improperly & $82(21 \%)$ & $8(17 \%)$ & $14(18 \%)$ & 35 (21\%) & $8(40 \%)$ & $17(22 \%)$ & \\
\hline Parked properly & 309 (79\%) & 38 (83\%) & 66 (82\%) & 132 (79\%) & $12(60 \%)$ & $61(78 \%)$ & \\
\hline
\end{tabular}

Statistics show $\mathrm{n}$ and percent in agreement. Bold indicates the correct answer based on local regulations. 


\section{Can you park your scooter there?}

Scooter riders' assessments of parking compliance for eight scenarios in 5 cities:

Cologne $(n=80)$, Auckland $(n=46)$, Milton Keynes $(n=167)$, Nashville $(n=20)$, and Rome $(n=78)$

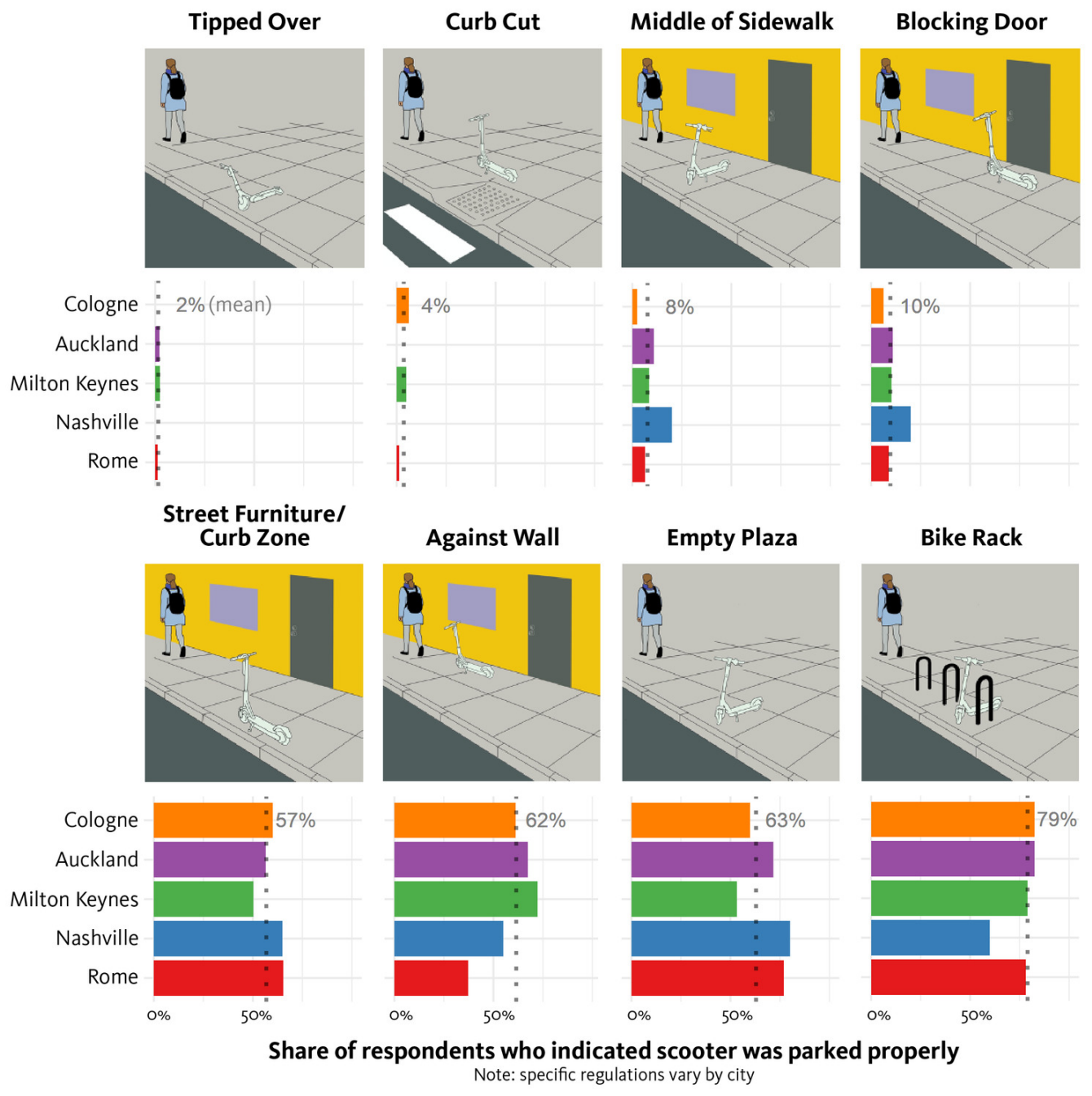

Figure 1. Scooter riders' assessments of parking compliance for eight scenarios.

Respondents largely relied on an intuitive understanding of whether scooters impede access by other travelers. Ninety percent of respondents correctly identified that a scooter parked in front of a door was improperly parked and 96 percent correctly identified a scooter in a sidewalk curb cut as improperly parked.

Respondents were less accurate and less certain about regulations that were not related to impeding access, such as parking a scooter at a bike rack. Further, regulations in some cities run counter to respondents' perceptions. For example, in Cologne, tipped over scooters do not violate local parking requirements. Yet nearly all (98.5\%) respondents-including all Cologne respondents $(\mathrm{n}=80)$-believed that tipped over scooters are improperly parked. 


\begin{tabular}{lc}
\hline & Number (and share) of respondents \\
\hline In-app reminders about the rules & $107(37 \%)$ \\
Fines & $51(18 \%)$ \\
More signage & $51(18 \%)$ \\
Increase parking supply & $46(16 \%)$ \\
Add an informational tag to scooters & $24(8.3 \%)$ \\
In-person training & $6(2.1 \%)$ \\
Other & $4(1.4 \%)$ \\
\hline $\mathrm{n}$ & $\mathrm{N}=391$ \\
\hline
\end{tabular}

When we subsequently showed respondents the parking rules in their city, the share who said that they had ever misparked jumped from 8.6 to 26 percent. This provides further evidence that local parking regulations do not always match scooter riders' assumptions and underlying rationales about parking rules. With these revised responses, respondents estimated that they misparked scooters after $7 \%$ of trips - on the high end of the range found in previous studies.

\section{Incentivizing proper scooter parking behaviors}

What do scooter users think scooter operators and local regulators should do to encourage proper scooter parking? Table 2 shows that more than one-third (37\%) of surveyed scooter users said that providing an in-app reminder at the end of a trip would be the best way to improve parking compliance. Similar percentages of riders believed that the most effective intervention for increasing parking compliance was fining riders for improperly parking (18\%), building physical signage to direct riders where to park (18\%), and adding additional designated scooter parking spaces (16\%).

Though we find that users mispark scooters at low rates (7\%), policy-makers, media, and resident concerns around scooter misparking remain high. Given riders' incomplete knowledge of parking regulations and preference for inapp reminders and signage as ways to improve parking behaviors, education campaigns may be the most effective first step in addressing misparking. But our results also suggest that parking regulations are not always clearly tied to the outcomes that riders intuit are the most important. Simplifying parking policies to focus on impeding access could benefit cities, operators, and riders alike.

\section{Acknowledgements}

Many thanks to Joachim Scheiner, Giulio Mattioli, Boris Braun, Lisa Ibott, Rachel Aldred, Daniel Work, and Caroline Janssen for feedback on the survey instrument. 
Submitted: January 30, 2021 AEDT, Accepted: February 12, 2021 AEDT

This is an open-access article distributed under the terms of the Creative Commons Attribution 4.0 International License (CCBY-SA-4.0). View this license's legal deed at https://creativecommons.org/ licenses/by-sa/4.0 and legal code at https://creativecommons.org/licenses/by-sa/4.0/legalcode for more information. 


\section{REFERENCES}

Brown, Anne, Nicholas J Klein, Calvin Thigpen, and Nicholas Williams. 2020. "Impeding Access: The Frequency and Characteristics of Improper Scooter, Bike, and Car Parking." Transportation Research Interdisciplinary Perspectives 4: 100099.

Fang, Kevin, Asha Weinstein Agrawal, Jeremy Steele, John Joseph Hunter, and Ashley M Hooper. 2018. "Where Do Riders Park Dockless, Shared Electric Scooters? Findings from San Jose, California.” Mineta Transportation Institute. https://scholarworks.sjsu.edu/cgi/ viewcontent.cgi? article $=1250 \&$ context $=$ mti_publications.

Gössling, Stefan. 2020. "Integrating E-Scooters in Urban Transportation: Problems, Policies, and the Prospect of System Change." Transportation Research Part D: Transport and Environment 79: 102230.

James, Owain, JI Swiderski, John Hicks, Denis Teoman, and Ralph Buehler. 2019. "Pedestrians and E-Scooters: An Initial Look at E-Scooter Parking and Perceptions by Riders and Non-Riders." Sustainability 11 (20): 5591.

Klein, Nicholas, Calvin Thigpen, and Anne Brown. 2021. "Why Scooter Riders Mispark and What to Do about It." OSF. February 11, 2021. https://osf.io/2ad7t/.

Livingston, Layron. 2020. "Suspension of Miami Scooter Pilot Program Has Some Happy, Others Sad.” Local 10, December 29, 2020. https://www.local10.com/news/local/2020/12/29/ suspension-of-miami-scooter-pilot-program-has-some-happy-others-sad/.

Portland Bureau of Transportation. 2018. "2018 E-Scooter Findings Report.” https://www.portlandoregon.gov/transportation/article/709719. 